\title{
ACERCAMIENTO A LA PRODUCGIÓN ORAL FORMAL EN LAS EXPOSICIONES ORALES DE UNIVERSITARIOS ITALIANOS: RELACIÓN ENTRE DISCURSO POCO FLUIDO E INCORRECGIÓN GRAMATICAL
}

\author{
Manuela del Carmen Rojas \\ Universidad de Cassino (Italia) \\ María Cecilia AINCIBURU \\ Nebrija Universidad (Madrid, España)
}

\section{RESUMEN}

Este artículo tiene como objetivo describir los rasgos predominantes en el discurso oral de diecisiete universitarios italianos aprendientes de español como lengua extranjera y su relación con la fluidez de la exposición oral académica. Para ello se señalan y analizan los fenómenos de alargamiento, diferentes tipos de pausa y titubeo, y sonidos paralingüísticos, asignándoles un valor estratégico a su producción. Seguidamente, estos rasgos se comparan con los fallos de corrección en la lengua para buscar, de este modo, una correlación entre los indicadores de fluidez y los errores gramaticales producidos.

PALABRAS CLAVE: discurso oral, fluidez, corrección gramatical, español, lengua extranjera, italianos.

\section{ABSTRACT}

The present paper is concerned with the description of the distinctive properties of the oral discourse of seventeen Italian university learning Spanish as a foreign language and their academic oral fluency. The phenomena of elongation, the different types of pause and hesitation, and the paralinguistic sounds identified and selected for analysis, with special focus on the strategic value of their production. These features are then compared with language correction errors in order to find a correlation between fluency indicators and the grammatical errors attested.

KEYWORDS: oral speech, fluency, grammatical correction, Spanish, foreign language, Italian. 


\section{INTRODUCCIÓN}

El presente artículo da a conocer los resultados de un estudio enmarcado dentro del ámbito de la investigación en Lingüística Aplicada, concretamente, en el Análisis del Discurso Oral Formal (en adelante, ADOF). La investigación se ha llevado a cabo en el ámbito académico, sin intervención didáctica previa y valiéndose solo de la experiencia discursiva de los alumnos con el objeto de caracterizar sus producciones orales en situaciones comunicativas auténticas. El propósito último ha sido analizar las estrategias lingüísticas y discursivas de los aprendientes ante las dificultades para gestionar oralmente la densidad informativa en Español Lengua Extranjera (en adelante, ELE).

Uno de los aportes fundamentales de los enfoques comunicativos y del soporte teórico y metodológico del Marco Común Europeo de Referencia para las Lenguas (MCER) consiste en destacar el papel que desempeña la lengua oral en el aprendizaje de lenguas extranjeras. Dicho papel no se limita a la práctica de la oralidad conversacional, sino a actividades programadas y llevadas a cabo en el aula que se orientan a presentar situaciones comunicativas con una serie de variantes y registros de la lengua para ampliar y desarrollar la competencia comunicativa oral, incluso predominante sobre la competencia escrita. Existen géneros orales de la práctica académica que es necesario explicitar en clase (Villar 2014); por esta razón, la creación de situaciones reales de comunicación en el aula es necesaria, tanto en primeras como en segundas lenguas, e implica un tratamiento de la competencia oral que comparte con la escrita las características de planificación, producción y evaluación. Las particularidades de la práctica académica invitan a dar prioridad a la enseñanza-aprendizaje de las intervenciones autónomas a las que Castellà Lidón y Vilà Santasusana (2005) llaman «monologadas», utilizando este término para distinguirlas de las formas dialogadas como los debates o las entrevistas ${ }^{1}$.

Dichas intervenciones son manifestaciones comunicativas de oralidad formal en las que se realiza un tratamiento especializado de la información que se transmite y por ello «requieren un alto grado de preparación, de elaboración e incluso, muchas veces, exigen el uso de la escritura (el apoyo de un guión, de unas notas, etc.)» (Calsamiglia y Tusón 2007: 16). En ellas, para lograr eficacia comunicativa, «se pretende la búsqueda de una expresión coherente, se amplía el repertorio léxico y se instruye en el manejo de diferentes fuentes de información»(Fuentes González 2011: 8). El desarrollo

\footnotetext{
${ }^{1}$ En debates y entrevistas hay intercambiabilidad de roles emisor-receptor a diferencia de la intervención monologada de relación unidireccional entre emisor y audiencia, aunque se prevé el turno de preguntas.
} 
de la competencia comunicativa en el ámbito académico comporta, pues, el dominio de estas formas de oralidad como parte de una educación lingüística más general. Por consiguiente:

Una de las finalidades de la enseñanza es conseguir que los alumnos sean capaces de comprender ideas complejas y de expresarlas de forma estructurada, compacta y precisa. De aquí se deriva la necesidad de enseñar a los alumnos a comunicarse en situaciones progresivamente más formales y a producir discursos elaborados y especializados, discursos que se alejan -y a la vez la complementan- de la oralidad directa y espontánea, propia de las situaciones cotidianas (Vilà Santasusana 2005: 11).

Dado que esta investigación analiza las exposiciones orales de estudiantes de grado como muestras del discurso oral universitario, se reseñarán las investigaciones previas que las han caracterizado, de forma que se tendrá en cuenta esa labor bibliográfica para señalar sus particularidades de acuerdo con la situación comunicativa y con su macroestructura, estableciendo su delimitación conceptual y diferenciándolas de otros géneros discursivos del ámbito de circulación estudiado.

Las 'presentaciones orales'² (presentations) se incluyen entre los géneros del aula en el estudio de Bellés y Fortanés (2004), referido a la lengua inglesa y se integran en una clasificación de los géneros académicos orales basada en la relación entre emisor y receptor. Por lo que se refiere a su denominación, González Ortiz (2004: 90), en su investigación con hablantes nativos de español, las denomina 'exposiciones orales' y las define como «discursos autónomos preparados con anterioridad, tienen un mayor contenido que los discursos no planificados, generalmente tratan de temas especializados...». Castellà Lidón y Vilà Santasusana (2005: 29) utilizan la misma denominación, 'exposición oral en clase (como un ejercicio del alumnado)', y la incluyen entre los géneros intermedios en el ámbito académico que adopta algunos rasgos de la escritura y requiere una complejidad y formalidad de elaboración alejada de los usos lingüísticos coloquiales. Por su parte, Sanz Álava (2005) utiliza tanto la denominación 'presentación oral' como 'ponencia' y 'ponente' para las producciones orales formales en ELE y las considera una práctica de los estudiantes como actividad preparatoria para su futuro desempeño académico y profesional.

En relación con sus características macroestructurales, Palou y Bosch (citados en Fuentes González 2011: 12) trazan un esquema básico para elaborar una exposición oral (Invención de las ideas - Disposición de las ideas - Exposición o elocución - Memorización - Actuación) conectado con la retórica clásica: Exordio (Captatio benevolentia - Partitio), Desarrollo

\footnotetext{
${ }^{2}$ Las comillas simples se emplean para aislar y destacar el significado del término.
} 
(Narratio - Confirmatio), Epílogo (Posita in rebus - Posita in affectibus). Y para su identificación como género académico en el ámbito de la enseñanza del español como lengua extranjera, la investigación llevada a cabo por Villar (2014) con aprendientes alemanes de ELE presenta datos concretos para delimitar la producción oral académica como género, tratarla conceptualmente, restringiendo su ámbito de aplicación (el aula universitaria) y definirla como 'presentación oral académica' (PAO).

Las denominaciones previas tienen ligeras variaciones en su etiqueta y algunas consideran la exposición en forma más o menos monológica, más o menos formal por el hecho de que el estudiante presenta temas en los que no ha realizado investigación primaria. En el caso de las muestras que constituyen el corpus de análisis de esta investigación, los rasgos centrales del género se pueden puntualizar así:

a. Situacionales: se trata de una exposición planificada previamente (y generalmente redactada) sobre un tema conocido, que un estudiante expone en clase ante sus compañeros (semilegos) y el docente (experto).

b. Macroestructurales: el tema se desarrolla con el esquema básico de Palou y Bosh (citados en Fuentes González 2011: 12), pero integra todas las «incidencias situacionales», dado que el estudiante tiene que presentarse, cargar la presentación gráfica, hacer frente a imprevistos, etc.

c. Psicoactitudinales: la situación comunicativa crea una tensión expresiva entre lo que el estudiante ha planificado y sabe de memoria y lo que tiene que gestionar como imprevisto, interrupción, fallos de la memoria o simulación a lo largo de su exposición.

Este último rasgo es fundamental en la caracterización como género de evaluación de la lengua extranjera y frecuentemente desaparece en las caracterizaciones. Para las producciones orales que se analizan en el presente artículo se ha adoptado la denominación de 'exposiciones orales en clase' (en adelante, EOC) ${ }^{3}$.

\section{RECURSOS LINGÜÍSTICOS PREDOMINANTES EN EL DISCURSO ORAL FORMAL}

Los rasgos lingüísticos que distinguen la oralidad de la escritura han sido objeto de estudio de muchos investigadores, especialmente en inglés, como sucede en otros ámbitos de investigación (Hughes 2013). La distin-

3 'Exposición oral en clase (como ejercicio del alumnado)' (Castellà y Vilà 2005: 29). 
ción oral/escrito no es solo una diferencia de canal de comunicación por el que se transmiten los mensajes, sino que implica también modalidades del lenguaje que se producen y se manifiestan según propiedades lingüísticas y factores contextuales propios. En términos de género textual, existe un continuum gradual de posibilidades intermedias entre los extremos de la oralidad y de la escritura, entre las que se indican los registros formal e informal y los registros intermedios de acuerdo con la relación de proximidad emisor/receptor, el saber y la experiencia compartidos, la cotidianidad, el grado de planificación y la finalidad de la comunicación (Llamas Saíz 2006). Con una perspectiva similar para superar la dicotomía oralidad/escritura, el estudio de Castellà Lidón y Vilà Santasusana (2005) aborda la clasificación de los géneros orales distinguiendo dos grandes grupos: los denominados géneros prototípicos y los géneros intermedios. Los primeros concentran las características de la lengua oral o de la lengua escrita, mientras que los segundos se alejan en mayor o menor grado del modo o del registro de la conversación coloquial (el modo oral prototípico) para adoptar algunas convenciones de la escritura. Dentro de estos últimos, los géneros discursivos formales intermedios en el ámbito académico, los autores colocan, precisamente, la exposición oral en clase (EOC) como ejercicio del alumnado, es decir, el género discursivo del que se ocupa el presente artículo.

Según puntualizamos al final del párrafo anterior, la objetividad propia del discurso escrito, fruto de un razonamiento y de una planificación consciente, está condicionada en el discurso oral formal, pese a su elaboración escrita previa, por la carga emotiva y de subjetividad que supone la actuación oral frente a un público. En relación con los rasgos de formalidad, característicos del discurso escrito (precisión y corrección normativa de la lengua), su presencia como guion en el discurso oral formal impregna el texto de algunos rasgos de oralidad coloquial como anacolutos, discordancias, muletillas y repeticiones. Por último, por su inmediatez, tanto el discurso oral coloquial como el formal se caracterizan por la presencia de interlocutores y de códigos no verbales que facilitan la comunicación inmediata emisor/receptor. Por consiguiente, se puede deducir que, si bien el discurso oral formal comparte algunos rasgos y aspectos tanto de la escritura como de la oralidad coloquial, posee características muy bien diferenciadas, que podemos sintetizar de la siguiente manera:

- presencia de un emisor único frente a un receptor múltiple.

- unidireccionalidad, con la posible alternancia de turnos de preguntas.

- contenido planificado de emisión libre.

- empleo de estrategias pragmático-discursivas.

- $\quad$ estrategias de cortesía lingüística. 
Para completar el cuadro de la actividad discursiva oral formal y de sus rasgos lingüístico-textuales, Briz et alii (2008: 105-130) señalan una serie de habilidades lingüísticas del orador, de tácticas verbales (claridad, precisión, corrección, concisión y elegancia) y de tácticas prosódicas (cualidades del control de la voz, volumen, velocidad, pausas, tono, flexibilidad) mediante las que el resultado final es elocutivamente más eficaz; además de los elementos externos a la producción oral formal como la elección del tipo de presentación (de memoria, leído, mixto), la adecuación al público y los recursos técnicos utilizados.

\section{FLUIDEZ Y CORRECCIÓN GRAMATICAL COMO PARÁMETROS DE LA EVALUACIÓN DEL DISCURSO ORAL FORMAL}

Como hemos dicho anteriormente, las EOC suelen utilizarse para la evaluación formativa o final en los cursos ELE, especialmente en la Universidad. Por su complejidad, la expresión oral en general requiere para su evaluación una serie de criterios objetivos que tengan en cuenta los aspectos cualitativos del uso de la lengua. Esto es, no solo la corrección gramatical, sino, también, la adecuación a la situación comunicativa, la fluidez y la coherencia del discurso. Estos criterios, en una versión más analítica, se encuentran en las directrices propuestas por el Marco Común Europeo de Referencia para las Lenguas (MCER, 2002), y en su desarrollo para el español en el Plan Curricular del Instituto Cervantes (PCIC, 2006). En las páginas 32-33 del MCER se especifican los rasgos de la lengua oral (formales, pragmáticos, estratégicos, incluyendo aspectos como pronunciación, entonación, fluidez, velocidad); y en el Cuadro 3 Niveles comunes de referencia: aspectos cualitativos del uso de la lengua hablada, se ilustra una escala según los niveles de competencia con los siguientes rasgos: alcance (repertorio lingüístico, vocabulario adecuado); corrección (en el uso de repertorio y estructuras de uso habitual); fluidez (continuidad, pausas en la enunciación); interacción (mantener conversaciones cara a cara) coherencia (enlace de elementos para formar secuencias). Los rasgos de fluidez y de corrección constituyen los dos parámetros de análisis del corpus oral analizado en el presente artículo.

\subsection{Sobre la fluidez}

La fluidez, entendida, en el caso de las EOC, como la cantidad de información que es capaz de transmitir en un discurso oral el hablante no nativo en un determinado lapso de tiempo incluye otro aspecto constitutivo, es decir, el que se refiere a la calidad, desarrollo y progresión de la informa- 
ción que se transmite ${ }^{4}$. Esta actividad discursiva se caracteriza, además, por la presencia de fenómenos de cuya frecuencia depende la mayor o menor calidad de la producción del hablante. Se trata de repeticiones, pausas, silencios, alargamientos vocálicos y consonánticos, enunciados truncados, vacilaciones que, en el caso del hablante no nativo, suelen acentuarse en su elocución por tratarse de una lengua diferente de la suya. En el ámbito de lo académico y de la expresión oral, Vázquez (2000: 17) considera que esta competencia comunicativa comprende la competencia lingüística (dominio de léxico, dominio sintáctico, dominio fonológico) y la fluidez que, a su vez, incluye la competencia estratégica (titubeos necesarios), la competencia discursiva (producir cadenas de habla, adaptar mensajes, no demasiada corrección) y la competencia cultural (gestos, mímica, valores) ${ }^{5}$.

En la breve reseña trazada por Escudero Martín (2006: 9-10) sobre las investigaciones y definiciones del término fluidez en enseñanza de lenguas se recogen los estudios que adoptan tanto el criterio cuantitativo como el cualitativo, esto es, no solo los autores que consideran la fluidez relacionada con el número de palabras habladas y la longitud media de expresiones en un tiempo fijado, sino también los que la relacionan con la cantidad de pausas vacías, de repetición de palabras y frases, y de autocorrecciones. A propósito de estos fenómenos, propios de la fluidez verbal en el contexto general del discurso, cabe señalar que su intencionalidad puede convertirlos en recursos fónicos positivos para la calidad de emisión del hablante, y esto vale en primeras lenguas y lenguas extranjeras (Mavrou 2016: 60). Tal como ocurre, en el caso de los hablantes nativos, cuando se recurre a ellos para conseguir efectos eficaces o para salir al paso de alguna necesidad comunicativa. Es el caso de las repeticiones de fragmentos o palabras en una clase magistral, por ejemplo:

La reiteración es una eficaz operación discursiva a la que se recurre en numerosos momentos de la clase magistral. Consiste fundamentalmente en repetir, de una manera u otra, cierto fragmento de lo ya emitido, para aclararlo, corregirlo, resaltarlo, evaluarlo o simplemente facilitar la progresión del discurso (Ortega Olivares y Labarta Postigo 2001: 57).

Verdaderos recursos fónicos del discurso oral son también las pausas, por su validez en cada uno de los niveles de la lengua, fonético-fonológico, sintáctico y semántico. Poch Olivé (2001) distingue entre pausas irrelevantes

${ }^{4}$ Una visión crítica del concepto de fluidez en lenguas extranjeras, en Mavrou (2016). De todos modos, como concepto operativo mínimo la fluidez se objetiva en cantidad de palabras por minuto.

${ }^{5}$ La misma dicotomía entre competencia lingüística y comunicativa, con mayor detalle en su asociación entre competencias estratégicas y productivas, en Cantero Serena (2008). 
y pausas relevantes en la transmisión oral de la información. Las primeras son pausas sonoras que el hablante utiliza en su discurso para organizar su pensamiento (eh, $e h h, h m, h m m$ ), rectificar la información (interrupción brusca de la producción de una palabra para decir luego la correcta) o pausas de titubeo (iniciar reiteradamente la producción de una misma palabra). Tales pausas, cuando son numerosas, pueden incluso caracterizar el discurso patológico; se trata, en efecto, de la emisión injustificada de «ruidos», «[ah::, ah::, uh::, ah::]» (Rodríguez Muñoz 2015: 28) y de una información reiterativa, es decir, temática, que no incorpora nada nuevo a lo dicho anteriormente.

Son también pausas sonoras o sonidos de apoyo los alargamientos vocálicos y consonánticos, fundamentales para el control de la producción oral, pues no interrumpen la elocución ni afectan a la comunicación, simplemente alargan el tiempo de la enunciación. Por el contrario, las pausas silenciosas se emplean en el discurso oral formal para recalcar la importancia de ciertos conceptos, hacer recapitulaciones y diferenciar los segmentos de la información que se transmite. En los dos casos se trata de verdaderas estrategias rítmicas (Rebollo Couto 1997) que disminuyen la velocidad del habla a los efectos de reorganizar el discurso como permiten «una gestión del tiempo de organización discursiva y posibilitan mayor fluencia y una sensible mejora de pronunciación en aprendices de lenguas extranjeras» (Rebollo Couto 1997: 668).

Menjura Torres (2007) sostiene que un fenómeno discursivo es positivo si el hablante lo emite intencionalmente, mientras que, si no es intencional, interviene negativamente en la calidad de la producción del discurso. La particular incidencia de estos recursos fónicos en la calidad del discurso oral formal del corpus comentado es objeto de estudio de los apartados 4 y 5 de este trabajo. Se verá cómo su mayor o menor presencia y su grado de intencionalidad permiten un acercamiento, en términos de fluidez, al valor positivo o negativo que los mismos adquieren, pese a que esta categorización de pausas positivas vs. negativas parece bastante lábil, ya que no siempre es posible, desde el punto de vista empírico, asegurar la intencionalidad de una pausa.

\subsection{Sobre la corrección}

Junto a la fluidez, la corrección es el otro parámetro clave de la comunicación, incluida en el MCER (2001: 32-33) como uno de los aspectos cualitativos del uso de la lengua hablada, dentro de una escala ilustrativa según los niveles de competencia. Para el español, la correspondencia de las escalas con las estructuras lingüísticas esperadas en cada nivel está pormenorizada en el Plan Curricular del Instituto Cervantes (PCIC, 2006). 
El concepto de corrección, estrechamente vinculado con el concepto de error, presupone, además, la noción de norma lingüística. De acuerdo con Vázquez (2009a), determinar el concepto de error sería emitir juicios de gramaticalidad, lo cual supondría tanto reconocer la validez de una norma lingüística como aceptar sus límites naturales y sociales, dada la riqueza de las normas lingüísticas del mundo hispanohablante. Ignorando esta variedad, los científicos tienden a estar más "preocupados en describir la norma que en describir los usos» (Cantero Serena 2014: 30). A este propósito, el PCIC, en relación con las normas cultas del español en sus diferentes localizaciones geográficas y con el material lingüístico de referencia seleccionado, aclara que este último corresponde:

preferentemente a la norma culta de la variedad centro-norte peninsular española. La selección de esta variedad se sustenta en los rasgos comunes que comparte con las restantes normas cultas del mundo hispánico y en su proyección dentro del modelo estandarizado prestigioso de la lengua para la propia comunidad hispánica... (PCIC, 2006).

Dado que la lengua empleada en las EOC se enmarca en un entorno lingüístico de aprendizaje formal de ELE y debe adecuarse a un discurso académico denso y complejo, los errores del corpus analizado en el presente artículo se han identificado teniendo en cuenta la norma culta arriba citada. Por ello, los errores o fallos de los alumnos expositores se entienden como desviación del «modelo estandarizado prestigioso de la lengua para la propia comunidad hispánica» $(\mathrm{PCIC}, 2006)^{6}$. Con respecto al concepto de 'desviación de la norma', es oportuno hacer una aclaración previa sobre la terminología empleada a este propósito. Fernández (1997), en relación con la distinción propuesta por Corder entre 'error' y 'falta', introduce algunos matices diferenciales en una escala que va desde «descuidos», «fallos», «olvidos», también presentes en la producción del hablante nativo, a los «errores» ${ }^{7}$ que se presentan en forma sistemática. Por su parte, investigaciones recientes que utilizan la metodología del análisis de errores en el ámbito de la enseñanza del español consideran también que hay diferencias sustanciales entre los términos de 'falta' y de 'error', según las bases sentadas por Corder, y utilizan (Alba Quiñones 2009) el de 'falta' para referirse a los errores de actuación. Dado que en la muestra de interlengua que aquí se comenta no se aborda el problema de la distinción entre errores y faltas, se adopta una terminología acorde con la situación de aprendizaje y con los fenómenos característicos del discurso oral formal. En efecto, teniendo en cuenta que titubeos, pausas, reinicios, junto a anacolutos o discordancias, son rasgos típicos de la oralidad y pueden ocasionar lapsus

\footnotetext{
${ }^{6}$ Vid. <www.cvc.cervantes.es/Ensenanza/biblioteca_ele/plan_curricular/norma.htm>.

7 Las comillas dobles son de la autora.
} 
tanto en hablantes nativos como en los aprendientes, cuando se utilice la palabra 'fallo' se entenderá que se alude a 'fallos en la corrección normativa de la lengua'.

El otro aspecto importante que Alba Quiñones (2009) señala en la obtención del corpus de la interlengua es el de la lengua compartida por los aprendientes que participan en la investigación debido a la facilidad con la que se puede categorizar el error en grupos con una misma L1. Las aportaciones de estas investigaciones a la enseñanza-aprendizaje de lenguas afines permiten abordar durante la fase de explicación de los errores identificados algunas consideraciones teóricas sobre los conceptos de transferencia positiva o negativa (interferencia) y sobre errores intra- e interlinguales. Se concluye que, desde un punto de vista cuantitativo, es considerable el número de errores que se pueden atribuir a una fuente interlingüística, como en el estudio de Sánchez Iglesias (2003: 190) que asume una hipótesis «fuertemente contrastivista», según precisa su autor. Precisamente en relación con la contrastividad, Vázquez (2009b) subraya que uno de los aspectos fundamentales sobre los que hay un amplio consenso en la bibliografía pertinente es el de la interferencia de la L1 como una de las causas de los errores por lo que, sostiene la autora, el análisis de los mismos debe ser contrastivo y a posteriori. De este modo, se explicarían los frecuentes recursos a la lengua materna como los préstamos y cambios de código, las traducciones literales, las acuñaciones léxicas basadas en la lengua meta que, por lo que se refiere a la lengua hablada, constituyen verdaderas estrategias de comunicación (Pinilla Gómez 2005).

Desde el punto de vista de la taxonomía adoptada, se han tomado como base las de Sánchez Iglesias (2003), aplicada a las producciones escritas en ELE de estudiantes italianos, y la de Campillos Llanos (2012) a producciones orales. El interés por estos dos estudios se debe a que, en el primero de ellos, tratándose de un trabajo sobre el contacto entre lenguas afines, se otorga mayor peso a la explicación de los errores interlinguales y, en el caso de Campillos Llanos (2012), al estudiar un corpus oral de aprendientes universitarios de ELE, se incluye el concepto de transferencia en la situación de aprendizaje de una lengua extranjera como una etiqueta más dentro de las categorías de análisis de errores.

En relación con los recursos fónicos identificados en el corpus y, de acuerdo con Menjura Torres (2007), la noción de intencionalidad o la ausencia de ella en los mismos son conceptos cualitativamente determinantes en el discurso oral formal de los no nativos, a lo que se añade la hipótesis admisible de su valor como estrategias frecuentes de la comunicación oral (Pinilla Gómez 2005). Teniendo en cuenta lo anteriormente señalado, se ha adoptado, pues, la opción descriptiva-explicativa para cada uno de los fallos o fenómenos identificados en el corpus, contextualizándolos dentro del marco de la oralidad académica con la finalidad de aportar 
datos sobre el desempeño lingüístico de un grupo de aprendientes italianos de ELE, pero sin la pretensión de trazar la taxonomía de errores de una muestra de interlengua oral a los efectos de clasificarlos según su previsibilidad o tratamiento.

\section{MÉtodo}

Mediante un diseño exploratorio se ha tratado de obtener datos empíricos de las exposiciones orales de un grupo de universitarios italianos con un nivel estimado de B2/C1 en ELE. Para llevar a cabo dicho estudio y describir la actuación global de los estudiantes expositores no se ha intervenido didácticamente en ninguna de sus fases, ni de búsqueda de materiales ni de planificación, de elaboración y de producción, ya que se trataba del comentario de la tesis con la que finalizaban el primer ciclo o trienio de formación. El propósito fundamental era obtener datos fiables sobre la relación entre la dificultad para expresar conceptos e ideas complejas y el nivel de competencia discursiva y lingüística, además de aportar datos empíricos como soporte de materiales destinados a una intervención didácticamente conveniente sobre la EOC como género académico. Las preguntas de investigación se han centrado en los siguientes aspectos:

1. ¿Existe algún tipo de correlación entre la corrección de la lengua y la fluidez en la actuación global de alumnos italianos cuando realizan exposiciones orales?

2. ¿Los rasgos lingüísticos de las producciones orales están vinculados con las dificultades para transmitir una información caracterizada por la densidad y complejidad de las ideas?

Las variables independientes estudiadas se relacionan con la competencia lingüística de los aprendientes de español. En cuanto a las variables dependientes, las mismas se refieren a las dificultades lingüísticas y discursivas (corrección gramatical, uso de pausas sonoras de titubeo y alargamientos) que se verifican durante las exposiciones orales en clase.

El corpus estudiado comprende diecisiete exposiciones orales en audio de alumnos del primer año de Lectorado del bienio de especialidad universitario (segundo ciclo de estudios) de la Facultad de Letras y Filosofía de la Universidad «La Sapienza» de Roma. Las transcripciones estarán disponibles dentro del proyecto Nebrija Academic (<https://slabank.talkbank.org/ access $/>$ ). El perfil medio de los participantes era el de aprendientes de ELE como primera o segunda lengua extranjera de especialidad, distinción basada en el número de asignaturas cursadas en lengua española (mayor como primera lengua extranjera). Sobre la base de esta distinción, se dividieron dos grupos de expositores a los efectos de verificar si las dificultades 
para transmitir un contenido denso y de léxico especializado dependen de un mayor o menor contacto con la lengua meta. El estudio exploratorio, sin grupo de control, se realizó atendiendo a cuatro parámetros de análisis relacionados con la macroestructura de la sesión expositiva y los rasgos lingüísticos predominantes. El presente artículo centra su atención en estos últimos, como se ilustra en la Tabla I:

TABLA I. Parámetro de análisis: rasgos lingüisticos predominantes ${ }^{8}$

\begin{tabular}{ll}
\hline \multicolumn{1}{c}{$[$ RECURSOS FÓNICOS $]$} & $\begin{array}{c}\text { FALLOS EN CORRECCIÓN } \\
\text { NORMATIVA DE LA LENGUA }\end{array}$ \\
\hline Alargamientos de vocales y consonantes & Nivel fónico \\
\hline Pausas silenciosas & Nivel morfosintáctico \\
\hline $\begin{array}{l}\text { Pausas sonoras (de organización } \\
\text { del discurso, de rectificación, de titubeo) }\end{array}$ & Nivel de léxico \\
\hline
\end{tabular}

Si bien el objetivo primordial del parámetro de estudio no es el análisis de errores, este resulta un paso previo para observar la corrección normativa de la lengua, por lo que se señalaron los fallos cometidos en los niveles fónico, morfosintáctico y de léxico. En relación con los otros rasgos lingüísticos, se analizaron los alargamientos vocálicos y consonánticos, las pausas silenciosas y sonoras como recursos fónicos fundamentales para el control de la producción oral.

Como tipo de discurso oral académico, la exposición ha sido planteada solo como un ejercicio del alumnado, sin evaluación final y con el consentimiento de los alumnos para su grabación en audio. Las sesiones expositivas y las grabaciones se realizaron en el horario de clases, con una media de duración de 13 minutos para cada una de ellas, incluyendo el turno de preguntas. Por acuerdo general entre los alumnos y el profesor, se unificó el tema y se optó por el comentario de la tesis de final de trienio de formación universitaria, cuya amplia temática abarca desde la lingüística de la traducción de textos al italiano (del inglés, del francés y del español), hasta aspectos culturales de la lengua extranjera de especialidad.

La transcripción de las grabaciones comprende la actuación del expositor (intervención monologada y turno de preguntas), y comprende una media de 1680 palabras por cada sesión expositiva. El análisis del corpus

\footnotetext{
${ }^{8}$ Para el análisis del parámetro indicado en Tabla I se han tomado como guías Rebollo Couto (1997), Cestero Mancera (2001), Ortega y Labarta (2001), Poch Olivé (2001) y Castellà y Vilà (2005).
} 
presenta una descripción general de los rasgos lingüísticos predominantes con un procesamiento estadístico mínimo de los mismos, para centrar la atención en su ejemplificación cualitativa.

\section{Resultados}

Uno de los rasgos importantes del discurso oral formal consiste, además de la precisión terminológica, en el uso normativo de la lengua y en su corrección morfosintáctica, prosódica y léxica. En el presente estudio, estos aspectos se observan y analizan contextualmente para evaluar el desempeño lingüístico del aprendiente en el marco discursivo y pragmático de la oralidad académica. En los Gráficos 1 y 2, se indican los resultados del análisis cuantitativo de los dos grupos de producciones orales, las de los 12 aprendientes de español como primera lengua extranjera de especialidad (en adelante, EPLE) y las de los 5 aprendientes de español como segunda lengua de especialidad (en adelante, ESLE). Este grupo, menos numeroso que el primero, se ha tomado en consideración para observar los rasgos predominantes en uno y otro grupo. Debido a esta desigualdad numérica, se indican en un mismo gráfico los porcentajes obtenidos de cada grupo.

\subsection{Rasgos lingüisticos I. Fallos en la corrección normativa de la lengua}

En el Gráfico 1 se evidencia una consideración cuantitativa de los fallos en los distintos niveles lingüísticos, que luego se describirán e ilustrarán destacados entre corchetes y en negrita.

GRÁFICO 1. Fallos en la corrección normativa de la lengua

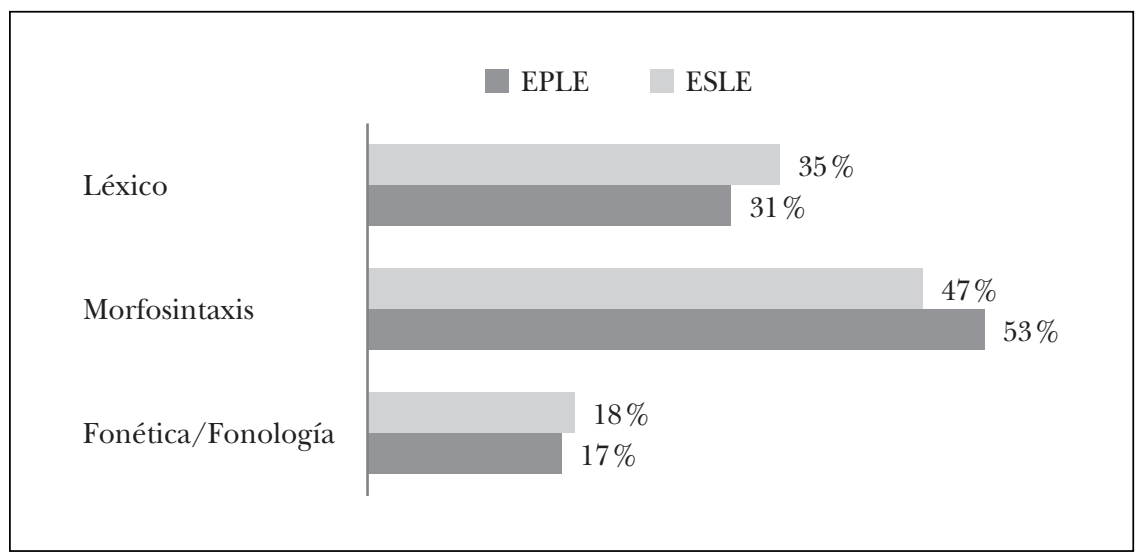


Como indica la longitud de las barras del Gráfico 1, no se observan diferencias relevantes en ninguno de los aspectos señalados entre los dos grupos. Para ejemplificar e indicar los porcentajes de frecuencia (sobre una media de 1680 palabras por cada exposición) de los distintos fenómenos en cada uno de los tres niveles, se los desglosa en varias etiquetas. Los más destacados cuantitativamente, en ambos grupos, son los interlinguales de Creación de palabras por interferencia con la L1 (con una diferencia relevante de porcentajes, el grupo ESLE de $14,75 \%$, frente al $20,17 \%$ del grupo ESLE) y de Cambio de código. De menor frecuencia son los de tipo intralinguales que atañen a la forma y significado. A continuación ${ }^{9}$, se ejemplifica cada uno de ellos:

- Creación de palabras por interferencia con la L1 (EOC12 en EPLE): «... son muchos los elementos que me [han colpido] tratando este tema...» (Italiano «colpire»; español «llamar la atención»).

- Cambio de código. Uso de palabras o expresiones de la L1 (EOC1 en ESLE): «... no [accade / no ocurre] lo mismo...» (Vacilación entre el italiano "accadere" y el español "ocurrir").

- Problemas de forma/significado

(EOC4 en ESLE): «... tiene que [reflejar] hmm [reflexionar] sobre el texto...» (Confusión semántica entre "reflejar" y "reflexionar", cuyo equivalente único en italiano es «riflettere»).

El segundo conjunto de fallos más destacables desde el punto de vista cuantitativo es el de los fenómenos del nivel fonético. Se observa una cierta uniformidad de frecuencia en ambos grupos en lo que atañe a la sonorización de la letra z por influencia de la lengua materna. Mientras que las disparidades son relevantes, también por atracción de la lengua materna, en la realización sonora del fonema /s / intervocálico y en final de palabra, mucho mayor en el grupo ESLE $(11,76 \%)$ que en el de EPLE $(1,80 \%)$; y en la pronunciación de la letra $g$ con las vocales $e, i$ como fonema /g/ oclusivo linguovelar sonoro solo localizable en las exposiciones del grupo EPLE. He aquí algunos ejemplos:

- Sonorización del fonema español $/ \theta$ / interdental con la letra $z$ (EOC1 en ESLE): «... enseñan [z] a de la locali[z]ación de videojuegos...»

- Transferencia de acentuación de la L1. De grave en español a esdrújula.

(EOC2 en EPLE): «... del [estereótipo] negativo contra de la mujer porque la mujer se desprecia desde hace siglos...»

${ }^{9}$ Convenciones de transcripción a partir de Briz (2008) y de Poch Olivé (2001). 
- Realización sonora del fonema español /s/ entre vocales y en final de sílaba (EOC2 en ESLE): «...e e[z] la parte central de la novela y e[z] más importante...»

- Realización de la consonante $g \operatorname{con} e, i$ como fonema /g/ oclusivo linguovelar sonoro (EOC10 en EPLE): «... la selección de los vinos más presti[g]iosos...»

El otro grupo de fallos destacados cuantitativamente se localiza en el nivel morfosintáctico, más específicamente en la categoría verbal. Hay diferencias relevantes de porcentajes entre ambos grupos. Por ejemplo, el que se refiere a la falta de concordancia entre verbo y sujeto, ausente en ESLE, quizá debido a un mayor control que incide, directamente, como veremos más adelante, en la fluidez de la exposición. Las otras diferencias que destacan se refieren a la concordancia del participio pasado con el sujeto activo ${ }^{10}$ por influencia de la L1, más frecuente en el grupo de EPLE $(2,52 \%)$ frente al de $\operatorname{ESLE}(0,84 \%)$; a la confusión de uso más frecuente en ESLE entre «Haber/Tener» $(5,04 \%)$, «Ser/Estar» $(3,36 \%)$, y «Hay/Estáestán» $(3,36 \%)$. A continuación, se proporcionan muestras de dos fenómenos cuantitativa y cualitativamente relevantes:

- Falta de concordancia sujeto-verbo

(EOC4 en EPLE): «... [esta lucha] entre el corazón y la razón [se manifiestan] en estos autodiálogos...»

- Concordancia del participio pasado con el sujeto activo (EOC1 en EPLE): «...han sido traducidos los refranes que [han padecidos] unas transformaciones en el tiempo...»

Los otros fallos de Morfosintaxis cuantitativamente numerosos están relacionados con las otras categorías gramaticales y con estructuras de la lengua meta en las que destaca el fenómeno de transferencia de la L1. Este es ligeramente mayor en el grupo ESLE (4,20\%) con respecto al grupo EPLE $(2,88 \%)$; mientras que el fenómeno de transferencia de género está ausente en ESLE. En general, no hay variaciones relevantes de porcentajes, salvo en lo que atañe a los Problemas en el uso de los cardinales, de mayor frecuencia en ESLE $(5,88 \%)$ con respecto a EPLE $(2,88 \%)$.

- Transferencia de estructuras de la L1 (EOC5 en EPLE): «... por eso [viene utilizado] también hoy en día...» (Verbo "venir" como auxiliar de la forma pasiva como la estructura italiana "venire" o "essere" + participio pasado del verbo conjugado).

\footnotetext{
${ }^{10}$ Pastor Cesteros (2001) localiza por debajo de un $40 \%$ en el nivel inicial y avanzado el fenómeno de concordancia participio pasado-sujeto activo en los tiempos compuestos, y observa que reaparece en el nivel superior de un aprendiz de L1 italiana.
} 
(EOC9 en EPLE): «... el profesor [me ha dicho de trabajar]...» (En italiano «verbo principal de voluntad + de + verbo subordinado en infinitivo»).

- Transferencia semántica de la L1 presente en el grupo EPLE (EOC1 en EPLE): «... no explican nada ehh con respecto a [la origen] de las palabras ...» (Transferencia de género del sustantivo italiano femenino "origine").

\subsection{Rasgos lingüisticos II: Recursos fónicos}

En este apartado, se presentan los porcentajes de uso en ambos grupos de los rasgos lingüísticos registrados dentro del corpus, correspondientes al empleo de alargamientos de vocales y consonantes, de pausas silenciosas, y de pausas sonoras de organización del discurso, rectificación y titubeo, como se ilustra en el gráfico siguiente:

GRÁFICO 2. Recursos fónicos utilizados por los dos grupos de informantes

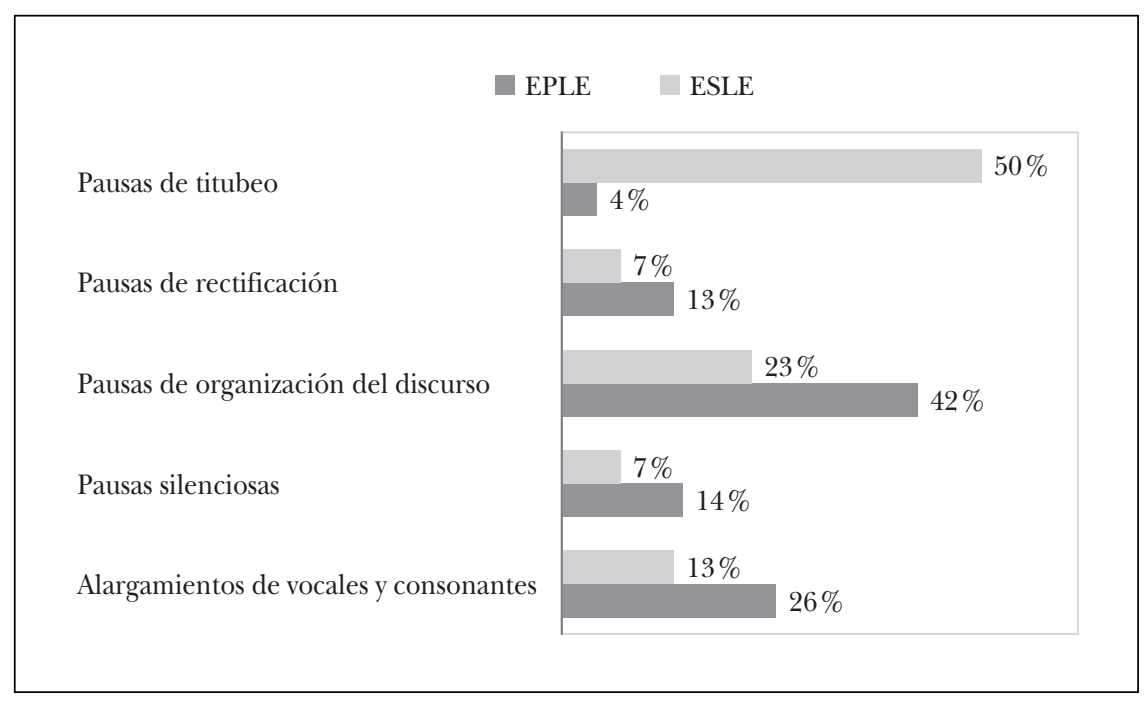

El análisis se va a centrar en aquellos recursos fónicos que son más frecuentes en ambos grupos, tal como se puede observar a simple vista por la altura de las barras en el Gráfico 2. Tras su identificación en el corpus, se han observado algunas coincidencias entre cada uno de estos recursos fónicos y los fallos más frecuentes en la corrección normativa de la lengua, que se describen y ejemplifican a continuación, destacados en negrita y entre corchetes: 
- Autocorrección de interferencias con la L1 mediante alargamiento de vocales y consonantes, y pausas sonoras de organización del discurso y rectificación

(EOC9 en EPLE): «... y ehh también la:: lo [stesso] /lo mismo pasa [por] la palabra por ejemplo cenador ehh se puede referir a alguien que cena...» (italiano stesso junto al español mismo).

(EOC1 en ESLE) «... según un estudio que está contenido en este ensayo [una:::]pequeña [per]/porcentaje del/de:: todos los los:: personajes de los vídeo juegos...» (femenino italiano percentuale, masculino español porcentaje).

- Vacilación en el empleo de la forma correcta en la lengua meta mediante alargamiento de vocales y consonantes, y pausas sonoras de organización, rectificación y titubeo

(EOC4 en EPLE): «... he tratado de encontrar en la cultura italiana un correspondiente ehh que [teniese] en cuenta esos aspectos y:: que se/que [tenie] /que tuviese el mismo significado...»

(EOC11 en EPLE): «... el valor de uso mínimo en este diccionario corresponde a tres y cero ocho ehh hay también palabras que:: ehh que hay/que están en los vi/en los villancicos que he analizado pero que no aparecen...»

- Transferencias de palabras y estructuras de la L1 con alargamiento de vocales y consonantes, y pausas sonoras de organización del discurso, rectificación y titubeo

(EOC7 en EPLE): «... una importante base que ehh deriva [dal/dalla civiltà] maya [e] azteca y ehh hay productos básicos como el maíz...» (Preposición italiana $d a$ y conjunción italiana $e$ ).

(EOC5 en EPLE): «... viene del [latino] angelicus y :: y [viene utilizado] con doble significado...» (Adjetivo italiano latino y estructura italiana para la pasiva «venire + participio pasado»).

Los ejemplos arriba indicados señalan que, si bien los titubeos, las pausas y los reinicios son fenómenos propios de la oralidad, incluso en las producciones de hablantes nativos ${ }^{11}$, por su frecuencia significativa en este corpus, son rasgos que inciden directamente en la fluidez de la expresión oral, pues no solo ralentizan el tiempo de la enunciación para permitir la organización de las ideas, sino que, además, son indicativos de vacilaciones o dudas para encontrar la palabra o expresión adecuadas en la lengua meta.

${ }^{11}$ Los titubeos y pausas se eliminan de la cuenta de palabras por minuto que constituye el criterio mínimo de fluidez. Dado que este criterio se liga a la producción verbal semántica, se podría discutir si algunas de las pausas o titubeos no constituyen en sí mismos un apoyo comunicativo al discurso y no solo un freno a la emisión de palabras (con detalle, en Vergara Padilla 2014). 


\section{Conclusiones}

En el presente artículo, se han presentado los resultados obtenidos del análisis de una muestra de interlengua oral cuyos sujetos son universitarios italianos aprendientes de ELE. El análisis se ha centrado en uno de los parámetros de estudio de la investigación, el que se refiere a los rasgos lingüísticos de exposiciones académicas orales en el ámbito de la enseñanza del español como lengua extranjera. Para situar los aportes de la presente investigación en dicho ámbito, se traza un breve resumen de los estudios recientes sobre el género, partiendo de los llevados a cabo por Villar (2011, 2013, 2014) que lo delimitan y definen como 'presentación académica oral' (PAO).

Las líneas de investigación de dichos estudios podrían agruparse en tres núcleos de interés: la macroestructura, la transmisión oral de la información y la instancia de evaluación. Los trabajos que se centran en el primero de ellos, describen el género y observan las secuencias textuales predominantes (Villar 2011), además de analizar contrastivamente la coocurrencia de rasgos lingüísticos en corpus de no nativos (estudiantes alemanes e italianos) (Ainciburu y Villar 2013). Por su parte, los que se detienen en algunos aspectos relacionados con la transmisión oral de la información observan la dificultad y escasos recursos (reformulaciones, recapitulaciones, repeticiones parafrásticas) del aprendiente de ELE para hacerlo adecuadamente y el uso frecuente de procedimientos de verbalización, como alargamientos, pausas rellenas, arranques falsos, autocorrecciones o búsqueda de la palabra adecuada (Rojas 2014; Vergara Padilla 2014 y 2015). Por último, en relación con el tercer núcleo de interés, destacan los trabajos de Villar (2011) y Ainciburu y Villar (2013) sobre la evaluación de las PAO vinculada a los contenidos específicos de asignaturas como ocurre, asimismo, con los de Vergara Padilla (2014 y 2015) y de Brown y Trincheri (2015).

En el presente artículo se describen las fallas gramaticales identificadas en el corpus, indicando la fuente básica, intralingual e interlingual, observando que, en casi todos los niveles de la lengua, destacan cuantitativamente las interferencias con la L1. Con respecto a los recursos fónicos, se identificaron en el corpus poniendo especial atención en los fragmentos de discurso en los que hay concurrencia con los fallos gramaticales. La descripción y comentario de los rasgos lingüísticos intentó responder a las preguntas de investigación, en primer lugar, si existe una correlación entre corrección de la lengua y fluidez de la enunciación y, en segundo lugar, si hay una vinculación entre los rasgos lingüísticos utilizados y la dificultad para transmitir un contenido complejo como el del discurso oral formal. Se puede concluir que: 
1. La presencia de los rasgos lingüísticos identificados es casi uniforme en ambos grupos, por lo que se deduce que no hay relación alguna entre la dificultad de los conceptos complejos por transmitir y la competencia lingüística de los aprendientes como primera o segunda lengua extranjera de especialidad.

2. Numéricamente, son más frecuentes los fallos interlinguales, atribuibles a factores como la traducción al español de la tesina escrita en italiano en la fase previa de preparación de la exposición.

3. Los fallos en la corrección normativa de la lengua son atribuibles también a la dificultad de los no nativos para transmitir un contenido denso con un léxico especializado.

4. Los recursos fónicos (pausas sonoras, alargamientos, titubeos), por su frecuencia y proximidad y/o coincidencia con los fallos de la lengua, son indicativos de vacilaciones, dudas o escasa fluidez en ELE.

5. Y, por último, que, de la frecuencia numérica de estos rasgos lingüísticos es posible inferir su influencia en el tiempo de enunciación y en la calidad del discurso. La alta frecuencia de recursos fónicos podría indicar su menor grado de intencionalidad, cualitativamente determinante en el discurso oral formal de este grupo de no nativos. Se podría admitir la hipótesis de su valor como estrategias para ralentizar el tiempo de enunciación y poder organizar las ideas o encontrar la palabra o expresión adecuadas en la L2.

Conviene aclarar que el estudio y comentario de esta muestra de interlengua se llevó a cabo sin una taxonomía previa, sino con posterioridad a su identificación en el corpus y a partir de clasificaciones ya existentes. El análisis de estos rasgos lingüísticos muestra cómo este grupo de aprendientes procesa la información gramatical en el marco de los aspectos discursivos y pragmáticos de la oralidad académica. En síntesis, se trata de un acercamiento a la producción oral formal de un grupo de hablantes no nativos, inserto en una situación de aprendizaje institucional de lenguas afines, sin la pretensión, como ya se ha puntualizado, de trazar una taxonomía de errores para clasificarlos, predecir futuras dificultades de aprendizaje o plantear su tratamiento adecuado. 


\section{BIBLIOGRAFÍA}

Ainciburu, María Cecilia y Claudia Villar (2013): «Coocurrencia de rasgos lingüísticos en la caracterización de la presentación académica oral EFE», Revista Nebrija de Lingüistica aplicada a la Enseñanza de las lenguas 13, 27-47.

Alba QuiÑones, Virginia (2009): «Análisis de errores en el campo del español como lengua extranjera. Algunas cuestiones metodológicas», Revista Nebrija de Lingüistica Aplicada 5, 1-16.

BARALO, Marta (2000): «El desarrollo de la expresión oral en el aula de E/LE», Carabela 47, 164-171.

BELLÉs Fortuño, Begoña e Inmaculada ForTANET Gómez (2004): «Handouts in conference presentations». En Inmaculada Fortanet Gómez et al. (eds.), Linguistic studies in academic and professional English, Castelló de la Plana: Publicaciones de la Universitat Jaume I, 63-76.

BRIz Gómez, Antonio (coord.) (2008): Saber hablar, Madrid: Santillana Ediciones Generales, S.L.

Brown, Ana Laura y Miranda Trincheri (2015): «Evaluación de presentaciones orales académicas: elaboración de descriptores basados en la performance». En Suplemento SIGNOS ELE (= 2013 III Congreso Internacional de Español: la Didáctica del Español como L1 y L2), 1-15.

Calsamiglia Blancafort, Helena y Amparo Tusón Valls (2007 [1999]): Las cosas del decir. Manual de análisis del discurso, Barcelona: Ariel.

CAmPillos Llanos, Leonardo (2012): La expresión oral en español lengua extranjera: interlengua y análisis de errores basado en corpus. Tesis doctoral. Madrid: Universidad Autónoma de Madrid. <hdl.handle.net/10486/660336>.

Cantero Serena, Francisco José (2008): «Complejidad y Competencia Comunicativa», Revista Horizontes de Lingüistica Aplicada 7/1, 71-87.

- (2014): «Adquisición de competencias fónicas». En Yolanda Congosto Martín et al. (eds.), Fonética Experimental, Educación Superior e Investigación, Madrid: Arco/Libros, 29-55.

CAstellà Lidón, Josep y Monserrat Vilà SANTASusana (2005): «La lengua oral formal: características lingüísticas y discursivas». En Montserrat Vilà Santasusana (coord.), El discurso oral formal Contenidos de aprendizaje y secuencias didácticas, Barcelona: Graó, 25-36.

Cestero Mancera, Ana María (2001): «Estrategias discursivas». En Graciela Vázquez (coord.), El discurso académico oral, Madrid: Edinumen, 43-57.

CONSEJO DE EuROPA (2002): Marco común europeo de referencia para las lenguas: aprendizaje, enseñanza, evaluación. <cvc.cervantes.es/ensenanza/biblioteca_ele/mar $\mathrm{co} />$.

Escudero Martín, María Jesús (2006): El diario, un recurso didáctico para la mejora de la fluidez oral en principiantes japoneses de ELE. Memoria de máster. Madrid: Universidad Antonio de Nebrija. 
FERNÁNDEZ, Sonsoles (1997): Interlengua y análisis de errores en el aprendizaje del español como lengua extranjera, Madrid: Edelsa.

Fuentes GonZÁlez, Antonio Daniel (2011): «Apuntes y reflexiones para una mejora de las habilidades lingüísticas y comunicativas en la exposición oral del alumnado universitario», Linred: Lingüistica en la Red 9, 1-36.

GONZÁlez ORTIZ, Lucy (2004): «La comprensión y producción de la exposición oral como técnica didáctica», Zona Próxima: Revista del Instituto de Estudios Superiores en Educación 5, 86-111.

Hugues, Rebecca (2013): Teaching and Researching: Speaking, London: Routledge.

Llamas SAíz, Carmen (2006): «Discurso oral y discurso escrito: una propuesta para enseñar sus peculiaridades lingüísticas en el aula de ELE». En Alfredo Álvarez (ed.), La competencia pragmática y la enseñanza del español como lengua extranjera (= ASELE Actas XVI), Oviedo: Universidad de Oviedo, 402-411.

Mavrou, Irini (2016): «Complejidad, precisión, fluidez y léxico: Una revisión», Moderna Språk 110/1, 49-69.

Menjura Torres, Martha Patricia (2007): «La fluidez discursiva oral. Una propuesta de evaluación», Ogigia 1, 7-16 <www.ogigia.es $>$.

Ortega Olivares, Jenaro y María Labarta Postigo (2001): «La reiteración». En Graciela Vázquez (coord.), El discurso académico oral, Madrid: Edinumen, 57-85.

PAstor Cesteros, Susana (2001): «La concordancia en la interlengua de los aprendices de español como lengua extranjera». En Susana Pastor Cesteros et al. (eds.), Estudios de Lingüística. Anexo 1, Alicante: Espagrafic, 5-60.

Pinilla Gómez, Raquel (2005): «La expresión oral». En Jesús Sánchez Lobato et al. (eds.), Vademécum para la formación de profesores. Enseñar español como segunda lengua (L2)/lengua extranjera (LE), Madrid: SGEL, 879-897.

Plan CuRricular Del Instituto Cervantes (PCIC, 2006): Niveles de referencia para el español. <cvc.cervantes.es/ensenanza/biblioteca_ele/plan_curricular_inven tario-b1-b2.html>.

Poch Olivé, Dolors (2001): «Recursos fónicos en la clase magistral». En Graciela Vázquez (coord.), El discurso académico oral, Madrid: Edinumen, 245-270.

Rebollo Couto, Leticia (1997): «Pausas y ritmo en la lengua oral. Didáctica de la pronunciación», ASELE. Actas VIII, 667-676. <www.cvc.cervantes.es/enseñanza/ biblioteca_ele/asele/pdf/08/08_0665.pd>.

RodRíGUEZ MuÑoz, Francisco José (2015): «Interrupciones y solapamientos en el discurso oral de hablantes con y sin síndrome de Asperger», RLA. Revista de Lingüistica Teórica y Aplicada 53/1, 13-34.

RojAs, Manuela del Carmen (2014): «Elementos inducidos y espontáneos en la macroestructura de las exposiciones orales de estudiantes italianos», Nebrija Procedia 3 (= Actas del II Congreso Internacional Nebrija en Lingüistica Aplicada a la Enseñanza de Lenguas: En camino hacia el plurilingüismo), 565-576.

SÁNCHEZ IgLESIAS, Jorge (2003): Errores, corrección y fosilización en la didáctica de lenguas afines: análisis de errores en la expresión escrita de estudiantes italianos de E/LE, Salamanca: Universidad de Salamanca.

SANZ ÁLAVA, Inmaculada (2000): «Las presentaciones orales en el español profesional», Actas del primer Congreso Internacional de Español con fines específicos, 133141 . 
- (2005): El español profesional y académico en el ámbito de la ingeniería civil. El discurso oral y escrito. Tesis doctoral. Valencia: Universidad de Valencia.

VÁzQUEz, Graciela (2000): La destreza oral. Conversar, exponer, argumentar, Madrid: Edelsa.

- (2009a): «El concepto de error: estado de la cuestión y posibles investigaciones», Revista Nebrija de Lingüistica Aplicada 5, 104-112.

- (2009b): «Análisis de errores, el concepto de corrección y el desarrollo de la autonomía», Revista Nebrija de Lingüística Aplicada 5, 113-121.

Vergara PAdilla, María Ángeles (2014): «Análisis contrastivo de los procedimientos de reformulación y evaluación en presentaciones orales académicas en E/LE e inglés como L1. Estudio de caso». Actas II Congreso Internacional Nebrija, 652-661.

- (2015): «Análisis contrastivo de los procedimientos de verbalización en presentaciones orales académicas en E/LE e inglés como L1. Estudio de caso», E-Aesla. Revista Digital de Lingüistica Aplicada 1, 1-14.

Vilà Santasusana, Monserrat (coord.) (2005) (1. a ed. 1999): El discurso oral formal. Contenidos de aprendizaje y secuencias didácticas, Barcelona: Graó.

VILlAR, Claudia Mariela (2011): «Las presentaciones académicas orales de los estudiantes alemanes de E/LE. Del discurso monológico al dialógico», Revista Nebrija de Lingüistica Aplicada 10/5, 130-172.

- (2014): Las presentaciones orales en E/LE de estudiantes alemanes. Un análisis macrotextual, discursivo y contextual del género en nativos y no nativos, Frankfurt am Main: Peter Lang. 